\title{
Persepsi Remaja tentang Peran Gender dan Gender Seksualitas di Kota Semarang
}

\author{
Boediarsih*) Zahroh Shaluhiyah**) Syamsulhuda BM**) \\ *) STIKES Karya Husada Semarang \\ Email : boediarsih@yahoo.com \\ **) Magister Promosi Kesehatan Universitas Diponegoro Semarang
}

\begin{abstract}
ABSTRAK
Pada dasarnya perempuan dan laki-laki berbeda pada karakteristik secara fisik dan perbedaan itu menjadi suatu masalah ketika dijadikan suatu ketidakadilan, pertentangan, penekanan dan penindasan, sehingga memunculkan adanya ketidakadilan dan ketidaksetaraan. Tujuan penelitian mengetahui faktor apa saja yang mempengaruhi persepsi remaja tentang peran gender dan gender seksualitas.Jenis penelitian ini kuantitatif dengan pendekatan cross sectional. Sampel sebanyak 395 yang diambil secara simple random sampling terhadap siswa SMA kelas XI di kota Semarang. Pengambilan data menggunakan kuesioner terstruktur. Analisis univariat dengan distribusi frekuensi, bivariat dengan chi square dan multivariat dengan regresi logistik.Hasil penelitian menunjukkan Responden mempunyai persepsi yang baik terhadap peran gender dan gender seksualitas 51,6\%. Ada hubungan antara asal tinggal, jenis kelamin, pengaruh teman sebaya dan pengalaman seksualitas dalam pacaran terhadap persepsi peran gender dan gender seksualitas pada responden.Jenis kelamin merupakan variabel yang dominan berpengaruh baik pada responden . Kata Kunci : remaja, persepsi, peran gender, gender seksualitas.
\end{abstract}

Kata Kunci: gender, seksual, remaja

\section{ABSTRACT}

Basically, women and men differ in physical characteristics, however, the difference and a problem when used as an injustice, conflict, suppression and oppression, which raises the existence of injustice and inequality. The aim of research to identify factors that influence adolescent perceptions of gender roles and gender sexuality. Quantitative research with cross sectional approach. A sample of 395 taken by simple random sampling of High School students of class XI in Semarang. Retrieving data using a structured questionnaire. univariate analysis with frequency distribution, bivariate with chi square and multivariate regression logistic. The research showed respondents have a good perception of gender roles and gender sexuality is 51,6\%, there is a relationship between the origin of living, sex, peer influence and experience sexuality in dating to the perception of gender roles and gender sexuality in respondents. And sex is the dominant variable contributes. Keywords: adolescence, perception, gender roles, gender sexuality.

Keywords: gender, sexual, adolescent

\section{PENDAHULUAN}

Santrock mengartikan remaja sebagai seseorang yang berada pada masa perkembangan transisi antara masa anak dan masa dewasa yang mencakup perubahan biologis, kognitif dan sosial- emosional. Perubahan biologis, kognitif, dan sosial yang terjadi berkisar dari perkembangan fungsi seksual, proses berpikir abstrak sampai pada kemandirian. Masa remaja dimulai kira-kira usia 10-13 tahun dan berakhir antara usia $18-22$ 
tahun. Pada setiap remaja harus menemui masa-masa dimana terdapat definisi baru mengenai peran gender mereka yang merupakan set harapan dalam menerapkan bagaimana seharusnya perempuan dan laki-laki berpikir, bertingkah laku, dan berperasaan.( Santrock, 2003).

Pada dasarnya, semua orang sepakat bahwa perempuan dan laki-laki berbeda pada karakteristik dari masingmasing secara fisik. Perbedaan alami yang dikenal dengan perbedaan jenis kelamin sebenarnya hanyalah segala perbedaan biologis yang dibawa sejak lahir antara perempuan dan laki-laki. Namun, perbedaan itu menjadi suatu masalah ketika dijadikan suatu ketidakadilan, pertentangan, penekanan dan penindasan satu sama lain.

Manifestasi dalam tatanan teknis pengasuhan akan tampak dalam pola asuh keluarga, sebagai contoh anak laki-laki cenderung mempunyai arti yang berhubungan dengan martabat, perlindungan dan tumpuan harapan keluarga bagi masa depan. Sedangkan anak perempuan mempunyai arti yang berhubungan dengan kepraktisan yaitu cenderung diarahkan untuk menyelesaikan kegiatan rumah tangga. Sebenarnya kondisi ini tidak ada salahnya, tetapi akan bermasalah ketika peran-peran yang telah diajarkan kemudian menempatkan salah satu jenis kelamin (baik perempuan maupun laki - laki) pada posisi yang tidak menguntungkan. Sebagai contoh jika seorang remaja laki - laki tidak mampu bersikap tegas akan dicap banci sedangkan jika remaja perempuan bersikap berani dan tegas akan dicap tomboi.

Pemerintah Indonesia telah mengeluarkan Inpres no. 9 tahun 2001 tentang Pengarus-Utamaan Gender (PUG) yang menyatakan bahwa seluruh program kegiatan pemerintah harus mengikutsertakan PUG dengan tujuan untuk menjamin penerapan kebijakan yang berperspektif jender. Perempuan telah diberi peluang yang sama dengan laki-laki dibidang pendidikan, namun persepsi masyarakat terhadap perempuan tidak mengalami perubahan yang berarti. Masih kuatnya anggapan bahwa pendidikan pada perempuan tujuannya adalah agar ia lebih mampu mendidik anak-anaknya.

Bentuk diskriminasi gender telah tampak pada masa remaja. Perempuan sering menjadi korban kekerasan dalam berpacaran. Kekerasan dalam pacaran merupakan perilaku atau tindakan seseorang dalam percintaan (pacaran) bila salah satu pihak merasa terpaksa, tersinggung, dan disakiti dengan apa yang telah dilakukan pasangannya. Berdasarkan data Legal Resources Center untuk Keadilan Jender dan Hak Asasi Manusia (LRC-KJHAM) Jawa Tengah menyatakan kasus kekerasan terhadap perempuan di 
Jawa Tengah selama satu semester terakhir, antara November 2012 hingga Juni 2013, LRC-KJHAM mencatat telah terjadi 301 kasus kekerasan terhadap perempuan dengan jumlah korban sebanyak 425 orang perempuan. Adapun bentuk kekerasan yang banyak dialami oleh perempuan di Jawa Tengah yaitu kekerasan seksual 265 kasus, kekerasan fisik dengan 100 kasus, dan disusul kekerasan psikis dengan 60 kasus. Sedangkan kelompok usia korban terdiri dari $47,77 \%$ perempuan dewasa, $40,47 \%$ anak-anak perempuan, dan 0,47\% lansia. (LRC-KJHAM, 2013).

Berdasarkan data tersebut dapat diketahui bahwa bentuk kekerasan yang paling sering dialami wanita adalah kekerasan seksual yaitu sebanyak 265 kasus atau 61,5\% dan pada umumnya kekerasan seksual ini dialami oleh kelompok umur remaja. Kekerasan seksual yang umumnya terjadi pada remaja dipicu oleh banyak faktor, salah satunya adalah kurangnya pengetahuan remaja tentang pendidikan seks yang benar. Informasi dan pengetahuan inilah yang menjadi dasar persepsi seorang remaja tentang seksualitas.

Tujuan dari penelitian ini adalah menganalisis Persepsi Peran Gender dan Gender Seksualitas pada Remaja di Kota Semarang Tahun 2014.

\section{METODE}

Penelitian ini menggunakan pendekatan survey. Rancangan penelitian ini adalah explanatory research dengan analisis korelational. Sedangkan dilihat dari dimensi waktu penelitian ini termasuk dalam studi cross sectional dimana waktu observasinya dilakukan sesaat.

Populasi dalam penelitian ini adalah remaja yang duduk di kelas XI SMA di Kota Semarang. Adapun remaja laki-laki di Kota Semarang berjumlah 13.854 orang, dan remaja perempuan berjumlah 16.289 orang. Sehingga total populasinya adalah 30.143 orang.

Adapun metode pengambilan sampel dengan teknik multistage random sampling, yaitu pertama dilakukan randomisasi terlebih dahulu dengan cara clusterisasi untuk menentukan lokasi sekolahan dengan membagi masingmasing wilayah menjadi 4 bagian, barat, timur, selatan dan utara. Kemudian untuk menentukan sekolahnya peneliti melakukan randomisasi dari masingmasing wilayah. Setelah diperoleh sekolahan yang dilakukan penelitian baru diambil respondennya secara simple random sampling berdasar list/daftar nama yang diperoleh dari sekolah terpilih. Dalam menentukan sampel peneliti melakukan perhitungan terhadap proporsi jumlah responden tiap wilayahnya, didapat hasil 395 siswa. 
Setelah masing -masing wilayah diketahui jumlah sampelnya kemudian di lakukan randomisasi terhadap sekolah yang digunakan untuk penelitian dan untuk menentukan respondennya dilakukan secara random sampling melalui undian.

Untuk menentukan tempat tinggal asal responden dibagi 2, yaitu Semarang kota meliputi: Jalan Gajah Mada, Kaligawe, Citarum, Gajah Raya, Srondol, Sriwijaya, Pandanaran, Panjaitan. Semarang pinggiran adalah wilayah selain jalan yang tercantum diatas.

\section{HASIL DAN PEMBAHASAN}

Hasil penelitian menunjukkan bahwa karakter responden, sebagian besar responden berjenis kelamin perempuan sebesar 241 (61\%), sedang laki-laki 154 (39\%), sedangkan untuk asal tempat tinggal, sebagian besar responden berasal dari tengah kota sebesar $218(55,2 \%)$, untuk yang dari pinggir kota sebesar 177 ( $44,8)$.

Untuk katagori pengaruh teman sebaya dibedakan atas baik dan kurang. Penelitian ini memperoleh hasil bahwa mayoritas responden dengan pengaruh kurang baik sebanyak 218 (55,2\%), sedang kategori pengalaman seksual dalam pacaran responden dibedakan atas mengalami $\operatorname{KDP}($ kekerasan dalam pacaran) dan tidak mengalami KDP.
Penelitian ini mayoritas responden mengalami KDP sebesar $265(67,1 \%)$.

Kategori persepsi peran gender dan gender seksualitas dibedakan atas baik dan kurang. Penelitian ini memperoleh hasil bahwa mayoritas responden dengan persepsi baik sebanyak 204 (51,6\%), untuk persepsi yang kurang 191 (48,4\%).

Persepsi peran gender dan gender seksualitas adalah kepercayaan normatif tentang bagaimana seharusnya seorang perempuan atau laki - laki dalam berperan, bertanggungjawab dalam kehidupan sehari hari, serta bagaimana mereka berpenampilan, bertindak dalam wilayah seksualitas.

Persepsi respoden yang kurang baik terdapat pada beberapa pertanyaan, yaitu sebanyak $74,7 \%$ responden berpendapat bahwa Perempuan tidak layak jika menyatakan cinta terlebih dahulu, sebanyak $72,4 \%$ responden berpersepsi bahwa Laki-laki harus jemput dan mengantar pulang perempuannya. Sebanyak $74,4 \%$ responden menganggap dalam pacaran yang lebih bernafsu adalah laki-laki. Dan sebanyak 88,6\% responden menyatakan jika terjadi kehamilan sebelum menikah maka wajar jika anak perempuan dikeluarkan dari sekolah, sebanyak 68,3\% responden menyatakan tidak menjadi aib jika laki-laki sering pulang tengah malam 
Sedangkan untuk pertanyaan yang terkait dangan persepsi peran gender, sebanyak $90,6 \%$ responden berpersepsi bahwa tanggung jawab bapak adalah mencari nafkah dan ibu mengasuh anak. Sebanyak 90,6\% responden berpersepsi bahwa Laki - laki sebagai pembuat keputusan sedangkan perempuan sebagai pendamping. Dan sebanyak 71,9\% responden berpersepsi bahwa aktifitas perempuan lebih baik ke arah kegiatan di dalam rumah, sedangkan kaum laki-laki lebih leluasa pada kegiatan di luar rumah.
Responden yang mempunyai persepsi kurang baik terhadap persepsi peran gender dan gender seksualitas umumnya menyetujui jika laki-laki itu lebih berhak memutuskan hubungan ketika proses pacaran dari pada seorang perempuan sebesar $72,7 \%$. Dalam hal ini memberikan arti bahwa laki-laki merasa lebih kuasa, lebih mempunyai power dan bargaining position sehingga lebih leluasa untuk memutuskan seorang perempuan.

\section{Hubungan antara Asal Tempat Tinggal dengan Persepsi Peran Gender dan Gender seksualitas}

Tabel 1. Distribusi responden menurut asal tempat tinggal terhadap Persepsi Peran Gender dan Gender seksualitas

\begin{tabular}{|l|l|l|l|l|l|l|l|}
\hline \multirow{2}{*}{ Asal tempat tinggal } & \multicolumn{6}{|c|}{ Persepsi Peran Gender dan Gender seksualitas } \\
\cline { 2 - 8 } & \multicolumn{2}{|l|}{ Baik } & \multicolumn{2}{|c|}{ Kurang } & \multicolumn{2}{|c|}{ Total } & p-value \\
\hline & $\mathrm{n}$ & $\%$ & $\mathrm{n}$ & $\%$ & $\mathrm{~N}$ & $\%$ & \multirow{2}{*}{0,0001} \\
\hline Pinggiran & 68 & 38,4 & 109 & 61,6 & 177 & 100 & \\
\hline Tengah Kota & 123 & 56,4 & 95 & 43,6 & 218 & 100 & \\
\hline
\end{tabular}

Tabel 1 menunjukkan bahwa responden dengan persepsi peran gender dan gender seksualitas kurang baik lebih banyak terdapat pada responden yang tinggal dipinggiran sebanyak $61,6 \%$ dibanding responden yang tinggal di tengah kota sebesar 43,6\%. Hasil uji statistik diperoleh nilai $\mathrm{p}=0,0001$. Hal ini membuktikan bahwa ada hubungan antara asal tempat tinggal responden dengan persepsi peran gender dan gender seksualitas (nilai $\mathrm{p}<0,05)$.

Asal tempat tinggal membawa pengaruh kemudahan akses informasi, dimana di tengah kota akan lebih mudah dari pada daerah pinggiran. Selain itu 
kompleksitas kultur ditengah kota lebih heterogen, sehingga reponden lebih terbuka terhadap peran gender dan gender seksualitas. Faktor lingkungan masyarakat pinggir kota sebagian besar juga masih beranggapan bahwa laki-laki superior dan wanita adalah inferior sehingga membentuk karakter bahwa laki-laki adalah orang yang lebih kuat sedangkan perempuan adalah mahluk yang lebih lemah yang mengutamakan emosional.

\section{Hubungan antara jenis kelamin dengan}

\section{Persepsi Peran Gender dan Gender}

\section{seksualitas}

Tabel 2 Distribusi responden menurut jenis kelamin terhadap Persepsi Peran Gender dan Gender seksualitas

\begin{tabular}{|c|l|l|l|l|l|l|l|}
\hline \multirow{2}{*}{$\begin{array}{c}\text { Jenis } \\
\text { Kelamin }\end{array}$} & \multicolumn{6}{|c|}{ Persepsi Peran Gender dan Gender seksualitas } \\
\cline { 2 - 7 } & \multicolumn{2}{|c|}{ Baik } & \multicolumn{2}{c|}{ Kurang } & \multicolumn{2}{c|}{ Total } & $p$-value \\
\hline \multirow{2}{*}{ Laki-laki } & 59 & 38,3 & 95 & 61,7 & 154 & 100 & 0.0001 \\
\hline Perempuan & 147 & 61 & 94 & 39 & 241 & 100 & \\
\hline
\end{tabular}

Tabel 2 menunjukkan bahwa responden dengan persepsi peran gender dan gender seksualitas kurang baik lebih banyak terdapat pada responden laki-laki sebanyak $61,7 \%$ dibanding responden perempuan sebanyak 39\%. Dengan demikian perempuan mempunyai kecenderungan berpersepsi baik terhadap peran gender dan gender seksualitas, dan sebaliknya untuk responden laki-laki. Hasil uji statistik diperoleh nilai $\mathrm{p}=0,0001$. Hal ini membuktikan bahwa ada hubungan antara jenis kelamin responden dengan persepsi peran gender dan gender seksualitas ( nilai $\mathrm{p}<0,05$ ).
Penelitian ini sesuai dengan pandangan gender secara tradisional, dimana pandangan ini membagi tugas secara kaku berdasarkan jenis kelamin. Laki laki yang mempunyai pandangan peran gender tradisional, tidak ingin perempuan menyamakan kepentingan dan minat diri sendiri dengan kepentingan keluarga secara keseluruhan, sedangkan isteri diharapkan mengakui kepentingan dan minat suami adalah untuk kepentingan bersama. Kekuasaan kepemimpinan dalam keluarga berada ditangan suami. Perempuan secara tradisional tinggal di rumah tidak bekerja (Fakih,1997) 


\section{Hubungan antara Pengaruh Teman}

\section{Sebaya dengan Persepsi Peran Gender}

\section{dan Gender seksualitas}

Tabel 3 Distribusi responden menurut pengaruh teman sebaya terhadap Persepsi Peran Gender dan Gender seksualitas

\begin{tabular}{|l|l|l|l|l|l|l|l|}
\hline \multirow{2}{*}{ Pengaruh Teman Sebaya } & \multicolumn{6}{|c|}{ Persepsi Peran Gender dan Gender seksualitas } \\
\cline { 2 - 8 } & \multicolumn{2}{|c|}{ Baik } & \multicolumn{2}{|c|}{ Kurang } & \multicolumn{2}{|c|}{ Total } & p value \\
\hline \multirow{2}{*}{ Baik } & $\mathrm{N}$ & $\%$ & $\mathrm{~N}$ & $\%$ & $\mathrm{~N}$ & $\%$ & \multirow{2}{*}{0,0001} \\
\hline Kurang & 134 & 75,7 & 43 & 24,3 & 177 & 100 & \\
\hline
\end{tabular}

Tabel 3. menunjukkan bahwa responden dengan persepsi peran gender dan gender seksualitas kurang baik lebih banyak terdapat pada responden dengan pengaruh teman sebaya kurang baik sebesar $67 \%$ dibanding responden dengan pengaruh teman sebaya yang baik sebesar $24,3 \%$. Hasil uji statistik nilai $\mathrm{p}=0,0001$. Hal ini membuktikan ada hubungan antara pengaruh teman sebaya responden dengan persepsi peran gender dan gender seksualitas ( nilai $\mathrm{p}<0,05$ ).

Dari beberapa pertanyaan yang ada, terlihat bahwa responden berada dalam lingkungan yang rentan terjadi pergaulan bebas, mereka sudah mulai mengakses pornografi, ada teman yang sudah melakukan hubungan seksual pra nikah. Selain itu mereka juga masih ikut persepsi tradisional bahwa lakilaki harus kaya , dimana adanya anggapan pacar harus dari kalangan kaya.
Meskipun lingkungan responden banyak yang sudah melakukan aktifitas seksual namun ternyata responden mempunyai self effikasi bahwa ia tidak akan mencobanya, selain itu juga adanya relasi yang baik sesama teman dimana antar teman akan saling menasehati.

Masa remaja memang masa pencarian jati diri namun dimasa ini pengembangan peer group sangat menonjol sehingga akan lebih dominan mempengaruhi aktifitas keseharian remaja. Hal ini dimungkinkan karena responden sebenarnya adalah remaja dengan berbagai ciri remajanya diantaranya adalah adanya ego untuk membantah/tidak mengikuti keinginan orang tua, dia lebih bisa menerima masukan dari teman sebaya.

MenurutConger (1991), Papalia dan Olds (2001), perkembangan sosial pada masa remaja lebih melibatkan kelompok teman sebaya di bandingkan orang tua. 
Pada remaja, pengaruh lingkungan dalam menentukan perilaku diakui cukup kuat.
Hubungan antara Pengalaman seksual responden dengan Persepsi Peran Gender dan Gender seksualitas

Tabel 4. Distribusi responden menurut pengalaman seksual terhadap Persepsi Peran Gender dan Gender seksualitas

\begin{tabular}{|l|r|r|r|r|r|r|l|}
\hline \multirow{2}{*}{$\begin{array}{l}\text { Pengalaman seksual dalam } \\
\text { pacaran }\end{array}$} & \multicolumn{6}{|c|}{ Persepsi Peran Gender dan Gender seksualitas } \\
\cline { 2 - 8 } & \multicolumn{2}{|c|}{ Baik } & \multicolumn{2}{|c|}{ Kurang } & \multicolumn{2}{c|}{ Total } & p-value \\
\hline \multirow{2}{*}{$\mathrm{n}$} & $\%$ & $\mathrm{n}$ & $\%$ & $\mathrm{n}$ & $\%$ & \\
\cline { 1 - 8 } & 125 & 47,2 & 140 & 52,8 & 265 & 100 & \multirow{2}{*}{0,005} \\
\hline TKDP & 81 & 62,3 & 49 & 37,7 & 130 & 100 & \\
\hline
\end{tabular}

Tabel 4 menunjukkan bahwa responden dengan persepsi peran gender dan gender seksualitas kurang baik lebih banyak terdapat pada responden yang mengalami KDP sebesar 52,8\% dibanding responden yang tidak mengalami KDP sebesar $37,7 \%$. Hasil penelitian menunjukkan bahwa $67,1 \%$ responden pernah mengalami Kekerasan dalam pacaran. Kekerasan yang dialami dalam bentuk : $24,3 \%$ responden mendapat ancaman akan diputus apabila berselisih pendapat dan $46,8 \%$ merasa dimonitoring oleh pacar melalui telepon, dan $48,9 \%$ pacarnya sering mengecek daftar sms atau telepon yang diterima.. Melihat jawaban diatas ternyata responden banyak yang mendapatkan kekerasan dalam psikologis, yaitu ancaman akan diputus.

Kekerasan psikis ini betujuan menurunkan keberhargaan diri seseorang, menimbulkan ketakutan, perasaan tertekan dan tidak berdaya. Perilaku yang muncul cenderung menunjukkan kecemburuan, posesif, dan pengendalian seperti memanggil nama pasangan dengan sebutan negatif (bodoh, jelek), cemburu berlebihan, dihina, diancam, dilarang berhubungan dengan teman, menggunakan handphone untuk mengecek pasangan sesering mungkin. Bentuk kekerasan ini sering terjadi namun jarang disadari sebagai kekerasan dianggap sebagai rasa sayang dari sang pacar.

Analisis bivariat menunjukkan $\mathrm{p}=<0,05$ sehingga penelitian ini terbukti bahwa pengalamann seksual dalam pacaran berhubungan dengan persepsi peran gender dan gender seksualitas.

Dengan menggunakan metode analisis Regresi Logistic diperoleh hasil bahwa dari 3 variabel bebas meliputi 
karakteristik asal tempat tinggal, jenis kelamin, pengaruh teman sebaya memiliki pengaruh terhadap persepsi remaja tentang peran gender dan gender seksualita. Dari 4 variabel tersebut, jenis kelamin merupakan variabel yang paling berpengaruh sebab mempunyai OR terbesar $(3,109)$.

\section{SIMPULAN}

Dari hasil penelitian ini dapat disimpulkan bahwa : Responden yang mempunyai persepsi yang baik terhadap peran gender dan gender seksualitas sebanyak 206 responden $(51,6 \%)$, dengan karakteristik terbanyak berasal dari tengah kota $(55,2 \%)$, jenis kelamin perempuan ( $61 \%$ ), pengaruh teman sebaya mayoritas kurang $(55,2 \%)$, pernah mengalami KDP $(67,1 \%)$. Ada hubungan antara asal tinggal $(0,0001)$, jenis kelamin $(0,0001$, pengaruh teman sebaya $(0,0001)$ dan pengalaman seksualitas dalam pacaran $(0,005)$ terhadap persepsi peran gender dan gender seksualitas. Terdapat 3 variabel bebas yang berpengaruh terhadap persepsi peran gender dan gender seksualitas yaitu asal tempat tinggal, jenis kelamin, pengaruh teman sebaya. Jenis Kelamin merupakan variabel yang dominan berpengaruh sebab mempunyai nilai OR tertinggi. Dari hasil penelitian ini diketahui bahwa jenis kelamin perempuan lebih baik dalam mempersepsikan kesetaraan peran gender dan gender seksualitas, sehingga diperlukan sosialisasi terhadap remaja lakilaki dan melibatkan volunteer laki laki guna memberikan pencerahan kepada kaumnya agar persepsi terhadap peran gender dan gender seksualitas semakin lebih baik jika dilakukan oleh sesama jenis kelaminnya.

\section{KEPUSTAKAAAN}

Bandura A.( 1977) Social Learning Theory, Prentice-hall. INC. Engewood Cliffs. New Jersey 07632.

Best, D.; J. Williams . (1997) Social Behavior and Applications; Sex, Gender, and Culture, Handbook of Cross-Cultural Psychology.

Fakih, Mansour. (1997) Analisis Gender dan Transformasi Sosial, Yogyakarta. Pustaka Pelajar.

Hartono. (2011) SPSS 16.0 Analisis data Statistika dan Penelitian, edisi ke2.

Herawati, Tanti. (2007) Budaya Jawa dan Kesetaraan Gender, Jurnal Komunikasi Massa Vol 1, No.1 Juli.

Hurlock, Elizabeth B. (2003) Psikologi Perkembangan Suatu Pendekatan Sepanjang Rentang Kehidupan, Jakarta. Erlangga.

LRC-KJHAM. ( 2013) Data Kejadian Kekerasan terhadap Perempuan. 
Muntari, Widi. (2013) Mengakhiri

Diskriminasi dan Pelanggaran Hak Asasi Perempuan Korban

Kekerasan Seksual dalam acara

Refleksi 29 Tahun Ratifikasi CEDAW dan Milad LRC-KJHAM Ke-14 Kamis,25 Juli.

Notoatmodjo, Soekidjo. (2007) Pendidikan dan Perilaku Kesehatan, Jakarta: Rineka Cipta.

RI. Pengarus-Utamaan Gender (PUG). Inpres no. 9 tahun 2001

RI.UU no.4/1979. Undang-undang Kesejahteraan Anak, Jakarta. 1979

Santrock, John W. (2003) Adolescence (Perkembangan Remaja), Jakarta. Erlangga..

Saptari, Ratna dan Brigitte Holzner. (1997) Perempuan Kerja dan Perubahan
Sosial. Sebuah Pengantar Studi Perempuan, Jakarta. Pustaka Utama Grafiti.

Stephen P Robbins, Timothy A Judge. (2009) Perilaku Organisasi Edisi 12, Jakarta. Salemba Empat.

Sufiarti. (2007) Faktor-faktor yang berpengaruh terhadap persepsi mhsw mengenai konsep dan kesetaraan gender (Tesis).

Walgito, Bimo. (2002) Pengantar Psikologi Umum, Yogyakarta. Andi Offset. 